\title{
Integration of ERa-PELP1-HER2 signaling by LSD1 (KDM1A / AOF2) offers combinatorial therapeutic opportunities to circumventing hormone resistance in breast cancer
}

\author{
Idriss M Bennani-Baiti* \\ See related research by Cortez et al., http://breast-cancer-research.com/content/14/4/R108
}

\begin{abstract}
LSD1, an epigenetic modifier, and PELP1, an estrogen receptor co-activator, integrate estrogen receptor ERa and HER2 receptor tyrosine kinase signaling to promote aromatase expression and hormone resistance in a preclinical model of post-menopausal breast cancer. In the previous issue of Breast Cancer Research, Cortez et al. show, for the first time, that knockdown or drug-mediated inhibition of PELP1 or LSD1 suppresses LSD1-mediated transcriptionally activating histone marks at ERa target genes, inhibits aromatase gene expression, and sensitizes hormone refractory breast cancer cells to tamoxifen or letrozole treatments. The relevance of PELP1-LSD1 signaling to other nuclear hormone receptor-dependent cancers and structural considerations for the selective drug targeting of LSD1 are further discussed in this editorial.
\end{abstract}

The fact that the majority of breast cancers express estrogen receptor-alpha $(E R \alpha)$ and thus are estrogendependent is both a curse and a blessing. It is a blessing because ER $\alpha$ is a well-defined molecular target that can be efficiently inhibited by drugs in adjuvant therapy to avert relapse as well as in the palliative treatment of advanced disease. It is a curse because a significant percentage of patients fail to respond to treatment and end up relapsing. Thus, for instance, although the ER $\alpha$ antagonist tamoxifen has proven to be one of the most successful drugs to be developed for the targeted therapy of cancer, more than half of patients with ER $\alpha$-positive

*Correspondence: ibennani@refgd.com

RefGD, The Reference Gene Database, Peter-Jordan Strasse, 1180 Vienna, Austria

BioMed Central o 2012 BioMed Central Ltd breast cancer show intrinsic or acquired tamoxifen resistance. Therefore, the mechanisms of ER $\alpha$ pathway drug resistance and the means of circumventing them represent high-priority fields in breast cancer research.

A predominant mechanism by which ER $\alpha$ drives breast cancer pathogenesis is the so-called nuclear genomic pathway. In this process, ER $\alpha$ recruits co-activator complexes to gene targets to potentiate their transcription. Co-activator complexes facilitate transcriptional activation in part by interacting with chromatin remodeling and histone-modifying enzymes which render the target chromatin template permissive to transcriptional activation. One such protein is LSD1 [1], a flavin adenine dinucleotide-dependent amine oxidase that catalyzes methyl group removal from methylated histone $\mathrm{H} 3$ lysine 4 (H3K4) and H3 lysine 9 (H3K9) to effect transcriptional repression or activation, respectively (to avoid gene symbol and species ambiguity [2], all genes discussed in this editorial are accompanied by their unique National Center for Biotechnology Information (NCBI) GeneID: LSD1, also known as KDM1 or AOF2; GeneID 23028; encodes lysine-specific histone demethylase 1). LSD1 demethylates $\mathrm{H} 3 \mathrm{~K} 9$ of $\mathrm{ER} \alpha$ chromatin targets in an estrogen-dependent manner, leading to hydrogen peroxide production and recruitment of 8-oxoguanine DNA glycosylase 1 and topoisomerase IIb, which promote DNA bending and the looping out of enhancer-promoter intervening DNA sequences [3].

In the previous issue of Breast Cancer Research, Vadlamudi and colleagues [1], from the University of Texas and from MD Anderson Cancer Center, implicate PELP1 (also known as HMX3 or MNAR; GeneID 27043; encodes proline-, glutamic acid-, and leucine-rich protein 1), a transcriptional co-activator that harbors neither DNA binding nor activation domains [4] and that couples LSD1 to ER $\alpha$ [5], in an ER $\alpha$-PELP1-LSD1 axis of hormone resistance in breast cancer [1]. 
Vadlamudi and colleagues [4] have shown that PELP1 is a dimethylated H3K4 (H3K4me2) and H3K9me2 reader and tilts LSD1 specificity toward H3K9me2, thus gearing LSD1 activity into transcriptional activation of ER $\alpha$ targets. PELP1 also induces the expression of the CYP19A1 gene (also known as cytochrome P450; GeneID 1588), which encodes aromatase, an estrogen synthase, thus promoting in situ estrogen synthesis and the ensuing autocrine or paracrine activation of ER $\alpha$ [6]. Aromatase induction was previously shown to be under positive control of the HER2 receptor tyrosine kinase protooncogene (also known as ERBB2 or CD340; GeneID 2064; encodes human epidermal growth factor receptor 2) [7], and Vadlamudi and colleagues show that the HER2-aromatase pathway is also under positive regulation by PELP1-LSD1 signaling [1], further implicating PELP1 and LSD1 in ER $\alpha$-driven breast cancer pathogenesis and hormone resistance. LSD1, therefore, may offer a molecular targeted therapy to counteract endocrine resistance and autocrine/paracrine resistance that often take place in breast cancer in pre- and postmenopausal women, respectively. To that effect, Vadlamudi and colleagues show, in preclinical models of post-menopausal breast cancer, that blocking LSD1 activity with a drug approved by the US Food and Drug Administration (FDA) inhibits aromatase activity and reduces tumor growth in vivo. Importantly, the authors also show that inhibiting LSD1 sensitizes tamoxifenresistant cells to tamoxifen, thus making the case for the use of LSD1-targeting drugs in combination therapies to circumvent tamoxifen resistance in breast cancer [1].

LSD1, which was first reported to be associated with cancer only three years ago, has since been found to possess oncogenic properties in several unrelated cancers ranging from bladder and lung cancers to sarcomas, and its inhibition reduces or blocks cell growth in many of these cancers (reviewed in [8,9]). Currently, two FDAapproved drugs can block LSD1 activity: pargyline (brand names: Eudatin, Eutonyl, Eutonyl-ten, Lopac-P-8013, and Supirdyl), an anti-hypertensive drug, and tranylcypromine (brand name: Parnate), which is used to treat major depressive episodes in adults. Both drugs are monoamine oxidase (MAO) inhibitors with relatively broad target spectra and are associated with a large number of side effects and drug interactions, thus severely limiting their clinical use. Vadlamudi and colleagues judiciously show that N-[(1S)-3-[3-(trans-2-aminocyclopropyl)phenoxy]1-(benzylcarbamoyl)propyl]benzamide, an experimental drug that was synthesized by Miyata and colleagues at Nagoya City University in Japan and that inhibits LSD1 at concentrations that are two orders of magnitude lower than those of pargyline and tranylcypromine [10], also efficiently inhibits aromatase production and breast cancer cell growth in vitro [1]. To date, the data show that targeting the ER $\alpha$-PELP1-LSD1 axis is likely to be a viable strategy in breast cancer treatment.

In addition to being associated with breast cancer, PELP1 is associated with other hormone-dependent cancers such as endometrial, ovarian, and prostate cancers [11-13] as well as with astrocytic brain tumors [14]. Although the latter are not traditionally thought of as hormone-dependent neoplasms, astrocytomas express various levels of several nuclear hormone receptors and co-activators, and normal astrocytes are responsive to estradiol modulation [14-16]. It would be of interest to investigate whether PELP1-LSD1 crosstalk also takes place in these cancers and, in the affirmative, whether drug targeting of the PELP1-LSD1 axis also makes therapeutic sense in these tumors. The rationale of such investigations is further supported by recent reports of the inhibition of growth, or induction of apoptosis, of prostate and astrocytic tumors following drug inhibition of LSD1 in in vitro and in vivo preclinical models $[17,18]$.

Together, the central role played by LSD1 in the ER $\alpha$-, PELP1-, and HER2-dependent biology of breast cancer and its hormone-dependent or -independent roles in other cancers warrant that new selective LSD1-targeting drugs approved for clinical use be urgently developed. In that regard, drugs that target the N-terminal LSD1 SWIRM domain, a six- $\alpha$-helical structural module frequently found in chromatin-associated proteins and important to LSD1 protein stability, might offer significantly improved selectivity, and thus fewer side effects, in comparison with current FDA-approved MAO inhibitors. In particular, the first and second $\alpha$ helices of the LSD1 SWIRM domain spanning residues 172 to 196 show insignificant sequence and structural homology to the closest human SWIRM domain-containing proteins, providing an ideal platform for the selective targeting of LSD1.

\section{Abbreviations}

ERa, estrogen receptor-alpha; FDA, US Food and Drug Administration; H3K4, H3 lysine 4; H3K9, H3 lysine 9; MAO, monoamine oxidase.

\section{Competing interests}

The author declares that he has no competing interests.

Published: 17 September 2012

\section{References}

1. Cortez V, Mann M, Tekmal S, Suzuki T, Miyata N, Rodriguez-Aguayo C, LopezBerestein G, Sood AK, Vadlamudi RK: Targeting the PELP1-KDM1 axis as a potential therapeutic strategy for breast cancer. Breast Cancer Res 2012, 14:R108.

2. Bennani-Baiti B, Bennani-Baiti IM: Gene symbol precision. Gene 2012, 491:103-109.

3. Perillo B, Ombra MN, Bertoni A, Cuozzo C, Sacchetti S, Sasso A, Chiariotti L, Malorni A, Abbondanza C, Avvedimento EV: DNA oxidation as triggered by H3K9me2 demethylation drives estrogen-induced gene expression. Science 2008, 319:202-206.

4. Brann DW, Zhang QG, Wang RM, Mahesh VB, Vadlamudi RK: PELP1 - a novel estrogen receptor-interacting protein. Mol Cell Endocrinol 2008, 290:2-7. 
5. Nair SS, Nair BC, Cortez V, Chakravarty D, Metzger E, Schule R, Brann DW, Tekmal RR, Vadlamudi RK: PELP1 is a reader of histone $\mathrm{H} 3$ methylation that facilitates oestrogen receptor-alpha target gene activation by regulating lysine demethylase 1 specificity. EMBO Rep 2010, 11:438-444.

6. Rajhans R, Nair HB, Nair SS, Cortez V, Ikuko K, Kirma NB, Zhou D, Holden AE, Brann DW, Chen S, Tekmal RR, Vadlamudi RK: Modulation of in situ estrogen synthesis by proline-, glutamic acid-, and leucine-rich protein-1: potential estrogen receptor autocrine signaling loop in breast cancer cells. Mol Endocrino/ 2008, 22:649-664.

7. Subbaramaiah K, Howe LR, Port ER, Brogi E, Fishman J, Liu CH, Hla T, Hudis C, Dannenberg AJ: HER-2/neu status is a determinant of mammary aromatase activity in vivo: evidence for a cyclooxygenase-2-dependent mechanism. Cancer Res 2006, 66:5504-5511.

8. Bennani-Baiti IM: Epigenetic and epigenomic mechanisms shape sarcoma and other mesenchymal tumor pathogenesis. Epigenomics 2011, 3:715-732.

9. Bennani-Baiti IM, Machado I, Llombart-Bosch A, Kovar H: Lysine-specific demethylase 1 (LSD1/KDM1A/AOF2/BHC110) is expressed and is an epigenetic drug target in chondrosarcoma, Ewing's sarcoma, osteosarcoma, and rhabdomyosarcoma. Hum Pathol 2012, 43:1300-1307.

10. Ueda R, Suzuki T, Mino K, Tsumoto H, Nakagawa H, Hasegawa M, Sasaki R, Mizukami T, Miyata N: Identification of cell-active lysine specific demethylase 1-selective inhibitors. J Am Chem Soc 2009, 131:17536-17537.

11. Vadlamudi RK, Balasenthil S, Broaddus RR, Gustafsson JA, Kumar R: Deregulation of estrogen receptor coactivator proline-, glutamic acid-, and leucine-rich protein-1/modulator of nongenomic activity of estrogen receptor in human endometrial tumors. J Clin Endocrinol Metab 2004, 89:6130-6138.

12. Chakravarty D, Roy SS, Babu CR, Dandamudi R, Curiel TJ, Vivas-Mejia P, LopezBerestein G, Sood AK, Vadlamudi RK: Therapeutic targeting of PELP1 prevents ovarian cancer growth and metastasis. Clin Cancer Res 2011, $17: 2250-2259$
13. Yang L, Ravindranathan P, Ramanan M, Kapur P, Hammes SR, Hsieh JT, Raj GV: Central role for PELP1 in nonandrogenic activation of the androgen receptor in prostate cancer. Mol Endocrinol 2012, 26:550-561.

14. Kefalopoulou Z, Tzelepi V, Zolota V, Grivas PD, Christopoulos C, Kalofonos H, Maraziotis T, Sotiropoulou-Bonikou G: Prognostic value of novel biomarkers in astrocytic brain tumors: nuclear receptor co-regulators AIB1, TIF2, and PELP1 are associated with high tumor grade and worse patient prognosis. J Neurooncol 2012, 106:23-31.

15. Carroll RS, Zhang J, Dashner K, Sar M, Black PM: Steroid hormone receptors in astrocytic neoplasms. Neurosurgery 1995, 37:496-503; discussion 503-494

16. Mong JA, Blutstein T: Estradiol modulation of astrocytic form and function: implications for hormonal control of synaptic communication. Neuroscience 2006, 138:967-975.

17. Singh MM, Manton CA, Bhat KP, Tsai WW, Aldape K, Barton MC, Chandra J: Inhibition of LSD1 sensitizes glioblastoma cells to histone deacetylase inhibitors. Neuro Oncol 2011, 13:894-903.

18. Willmann D, Lim S, Wetzel S, Metzger E, Jandausch A, WilkW, Jung M, Forne I, Imhof A, Janzer A, Kirfel J, Waldmann H, Schüle R, Buettner R: Impairment of prostate cancer cell growth by a selective and reversible lysine-specific demethylase 1 inhibitor. Int J Cancer 2012, Mar 24 [Epub ahead of print].

doi:10.1186/bcr3249

Cite this article as: Bennani-Baiti IM: Integration of ERa-PELP1-HER2 signaling by LSD1 (KDM1A / AOF2) offers combinatorial therapeutic opportunities to circumventing hormone resistance in breast cancer. Breast Cancer Research 2012, 14:112 